\title{
DELIVERING LINKING VALUE THROUGH EVENTS: INVESTIGATING COMMUNAL AND EXPERIENTIAL DRIVERS OF LOYALTY
}

Jan Drengner, Chemnitz University of Technology, Germany

Steffen Jahn, Chemnitz University of Technology, Germany

Hansjoerg Gaus, Saarland University, Germany

T. Bettina Cornwell, University of Oregon, USA

\begin{abstract}
Music, sport, art and food related events are interesting branded products on their own right. With their potential to bring consumers together surrounding a shared interest, they reveal latent consumption communities. Presented here is a study of a music festival, where a temporal sense of community was developed. Results of a survey of participants show that a positive socioemotional experience and a temporal sense of community while attending the event are strong predictors of repatronage and positive word of mouth and in some instances more explanatory than traditional measures such as overall satisfaction.
\end{abstract}

References available upon request 